\title{
Archéopages
}

Archéopages Archéologie et société

40 | 04-07/2014

Villages

\section{Le puits en milieu urbain}

\section{Odile Maufras}

\section{(2) OpenEdition}

\section{Journals}

Édition électronique

URL : https://journals.openedition.org/archeopages/653

DOI : 10.4000/archeopages.653

ISSN : 2269-9872

\section{Éditeur}

INRAP - Institut national de recherches archéologiques préventives

\section{Édition imprimée}

Date de publication : 1 juin 2015

Pagination : 164-165

ISSN : 1622-8545

\section{Référence électronique}

Odile Maufras, «Le puits en milieu urbain », Archéopages [En ligne], 40 | 04-07/2014, mis en ligne le 01 juillet 2016, consulté le 26 janvier 2022. URL : http://journals.openedition.org/archeopages/653 ; DOI : https://doi.org/10.4000/archeopages.653 


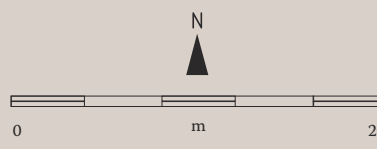

A: Immeuble

B: Parking

C: Voirie

$\square$ Palier de sécurité

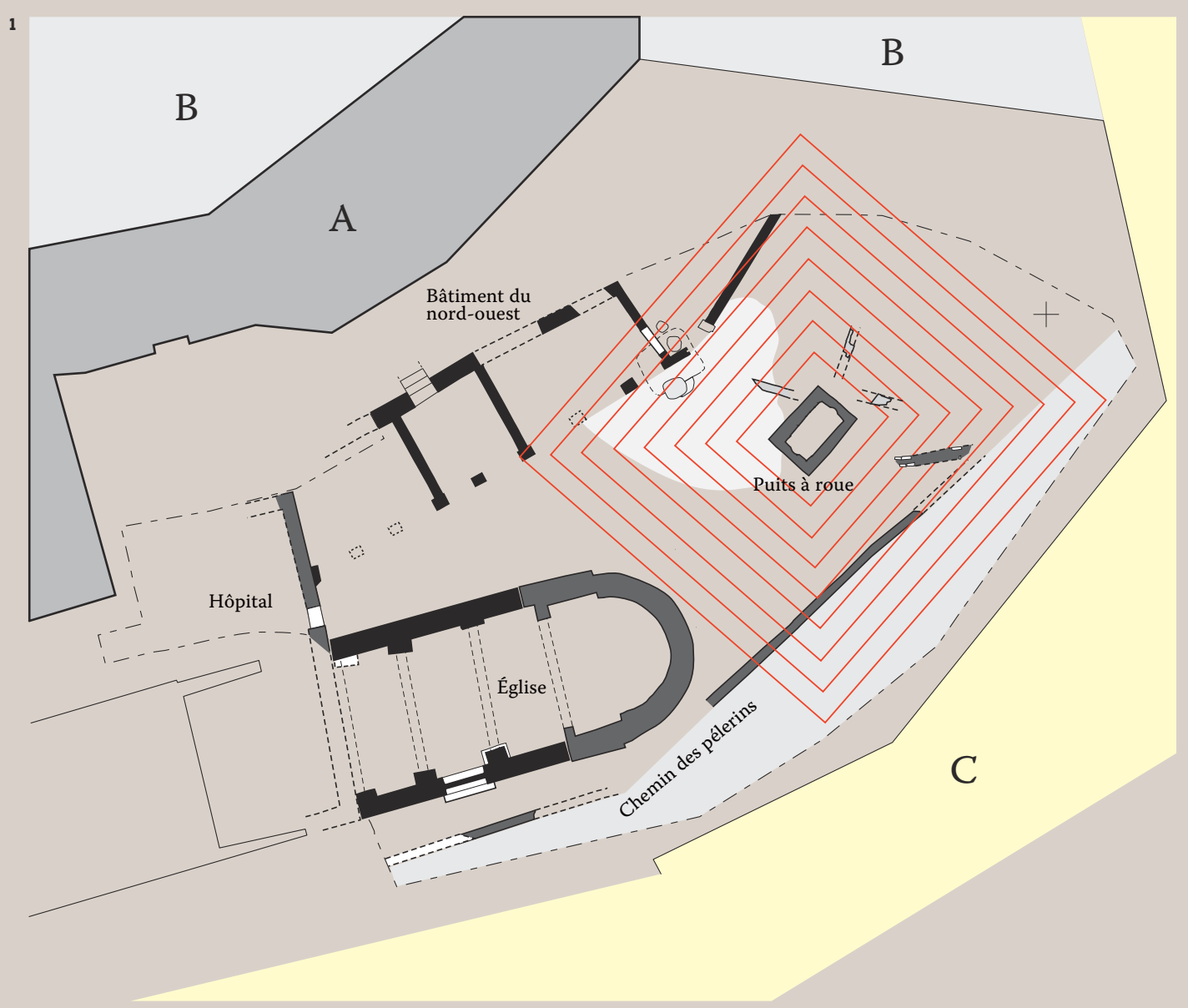

1. Plan des vestiges de

|'hôpital du Saint-Esprit à Montpellier dans le cadre contraint des limites de

fouille. Les tracés rouges figurent l'emprise des huit paliers qui auraient été nécessaires pour vider le puits à roue sur $10 \mathrm{~m}$ de profondeur. Ici, le puits n'a pas été fouillé.

2. Les puits antiques du site des Carmes à Nîmes en fin d'opération : leur fouille n'est intervenue

qu'après l'exploitation complète des vestiges alentour.

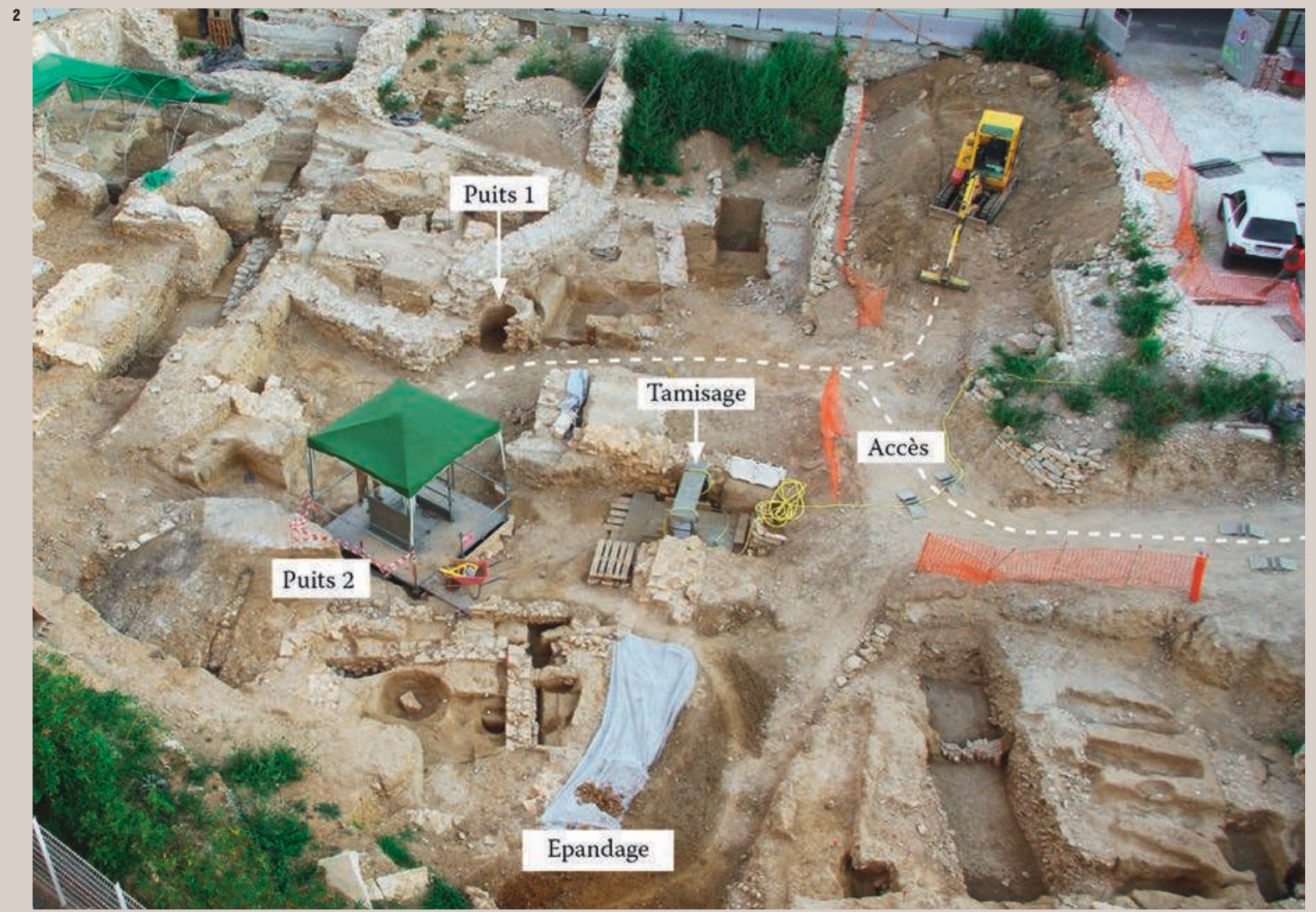


Le puits en milieu urbain

Odile Maufras, Inrap, UMR 5140

«Archéologie des sociétés méditerranéennes"

Le milieu urbain se caractérise par deux traits qui limitent le succès de l'enquête archéologique. L'un est la mauvaise conservation des vestiges anciens que la multitude des caves modernes a fait disparaître. Les élévations antiques et médiévales sont rarement conservées, les sols et une partie du sous-sol manquent. Ne restent de ces périodes que les aménagements qui impactent très profondément le terrain: fondations des constructions monumentales et puits. Autre trait: la densité et l'imbrication des vestiges sur plusieurs mètres d'épaisseur.

Dans ce contexte, les puits sont des structures prometteuses. Aménagés sur une grande profondeur, ils recèlent un volume de plusieurs mètres cubes de vestiges largement issus de la surface et susceptibles de documenter les parties disparues des sites. Ainsi, l'archéologue n'aura de cesse que de curer les puits. Cependant, leur fouille n'est pas aisée en milieu urbain. Le puits n'y est pas isolé, aussi ne peut-on envisager de le traiter manuellement par tranches de 1,30 $\mathrm{m}$ de profondeur avec élargissement mécanique de la fenêtre de fouille par autant de paliers de sécurité que de tranches, sans avoir au préalable fouillé l'intégralité des vestiges environnants. Et cela sur une surface d'autant plus vaste que le puits est profond. Or, en milieu urbain, les surfaces de fouille sont restreintes. En 1998, à Montpellier, un puits à roue de l'hôpital du Saint-Esprit a été mis au jour (Maufras, 1999). Sa fouille par paliers n'a pas été praticable, à la fois par la présence tout alentour d'un cimetière dense, également faute de place [ill. 1]. Ici, l'équipe archéologique s'est contentée des quelques fragments d'architecture retrouvés dans le mètre supérieur pour illustrer les élévations de l'établissement. En 2005, aux abords de la cathédrale de Nîmes, c'est

l'interdiction de fouiller sous le niveau inférieur des fondations du projet d'aménagement, outre son emprise réduite, qui a interdit la réalisation de paliers. La structure d'Archéopuits n'existait pas encore et seul le mètre supérieur a été fouillé. Il a livré une partie de la superstructure du puits et l'on attendait beaucoup de la fouille plus profonde qui n'a pu être réalisée (Maufras et al., 2007). En 2011, l'opération menée sur une partie du couvent des Carmes de Nîmes a mis au jour deux puits du $\mathrm{I}^{\mathrm{er}}$ siècle avant notre ère. Leur fouille avait été prévue, dès l'élaboration du projet d'intervention, et envisagée en fin de chantier. Ils n'ont été accessibles que lorsque leur environnement a été fouillé sur la surface nécessaire à la mise en place de la plate-forme, de la station de tamisage au stockage des terres extraites et à la circulation d'un engin, soit 30 à $40 \mathrm{~m}^{2}$ [ill. 2]. La fouille de ces puits a semblé décevante dans un premier temps : l'abaissement de la nappe phréatique n'a pas permis la conservation des matières organiques et aucun élément architectural n'y a été rejeté. Nous n'avons donc collecté que peu d'indices sur l'environnement paysagé et monumental du site, et aucun objet ou aménagement en bois, cuir ou tissu. Cependant, le dépôt abondant de vaisselle dans l'un des puits a permis de saisir la longue durée d'utilisation que les niveaux de surface ne permettaient pas de déceler tandis que l'autre, aménagé dans un espace d'atelier que l'on croyait voué à la tannerie, a livré quelques ossements qui ont mis en évidence une activité de pelleterie, notamment de fourrure d'hermine, que nous n'avions pas soupçonnée.

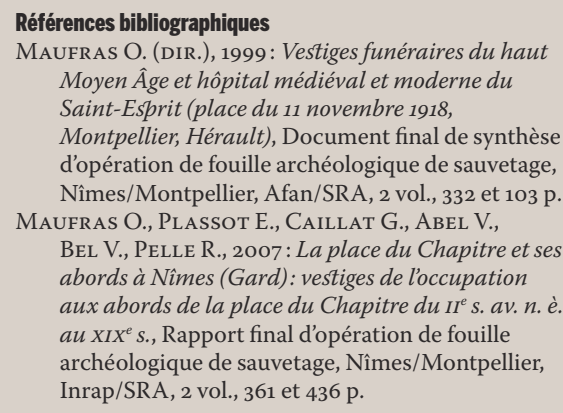

\section{Les remplissages de deux puits} d'un temple à Magalas

Olivier Ginouvez, Inrap, UMR 5140

«Archéologie des sociétés méditerranéennes »

Le site archéologique des terrasses de Montfau avoisine le pied d'un important oppidum fréquenté à partir du $\mathrm{VI}^{\mathrm{e}}$ siècle avant notre ère. Fouillée anciennement, l'agglomération protohistorique occupe les abords d'un itinéraire important reliant le littoral au rebord méridional du Massif central, via la cité de Béziers établie à $20 \mathrm{~km}$ plus au sud. Sur une surface de $9300 \mathrm{~m}^{2}$, l'étude a concerné les vestiges d'un sanctuaire avoisiné par une série de bâtiments vraisemblablement voués à l'accueil et à l'hébergement des pèlerins. Les premiers aménagements sont pour l'instant datés du début $\mathrm{du} \mathrm{I}^{\mathrm{er}}$ siècle avant notre ère et consistent en un vaste enclos quadrangulaire, délimité par un fossé comblé de fragments d'amphores italiques. Le site répond dès cette date à une fonction religieuse que les remaniements à venir ne feront que maintenir, au prix de modifications architecturales sans cesse renouvelées jusqu'au début du III $^{\mathrm{e}}$ siècle. Le sanctuaire primitif est matérialisé par son périmètre fossoyé. Un puits, quelques fosses isolées et deux fours à céramique lui sont également associés, mais le seul temple identifié dans le cadre de la fouille relève de la phase suivante. Peu après le changement d'ère, un mur maçonné est substitué au fossé précédent. Le nouveau péribole comprend dès lors un bâtiment de culte et 